\title{
Original
}

\section{Fasting plasma glucose after intensive insulin therapy predicted long-term glycemic control in newly diagnosed type 2 diabetic patients}

\author{
Jianbin Liu, Juan Liu, Donghong Fang, Liehua Liu, Zhimin Huang, Xuesi Wan, Xiaopei Cao and \\ Yanbing Li
}

Endocrinology and Diabetes Center, The First Affiliated Hospital of Sun Yat-sen University, Guangzhou 510080, China

\begin{abstract}
Short term intensive insulin therapy has been reported to induce long term euglycemia remission in patients with newly diagnosed type 2 diabetes mellitus, but the factors that are responsible for long-term remission or hyperglycemia relapse are unknown. Original data of 188 patients with newly diagnosed type 2 diabetes treated with short term intensive insulin therapy was reanalyzed. Patients who maintained glycemic control for 12 months with only life style intervention were defined as remission while those who failed to maintain glycemic control for 12 months as hyperglycemia relapse. Relationships of metabolic control, $\beta$ cell function and insulin sensitivity with remission time and hyperglycemia relapse were explored. Totally 93 patients achieved 12-month euglycemic remission. Substantial improvement in blood glucose, parameters of $\beta$ cell function and insulin sensitivity were obtained in both remission and relapse patients. The duration of remission was correlated with fasting plasma glucose measured after cessation of continuous subcutaneous insulin infusion (CSII) therapy (fasting plasma glucose (FPG) after CSII, $r=-0.349, p<0.0001$ ). Multivariate logistic regression show that FPG after CSII was independent predictor of hyperglycemic relapse (Odds ratio $=1.585, p=0.001$ ). All patients were stratified into three groups according FPG after CSII. As multivariate Cox proportional hazards regression demonstrated, compared with the patients with $\mathrm{FPG}<6.1 \mathrm{mmol} / \mathrm{L}$, risk for hyperglycemia relapse was increased $60 \%$ in those with 6.1 $\mathrm{mmol} / \mathrm{L} \leq \mathrm{FPG} \leq 7.0 \mathrm{mmol} / \mathrm{L}$ (Hazard ratio=1.60, $p=0.049$ ), and 1.69 folds in those with $\mathrm{FPG}>7.0 \mathrm{mmol} / \mathrm{L}$ (Hazard ratio=2.69, $p<0.0001)$. Our study demonstrated that fasting plasma glucose after intensive insulin therapy is a convenient and significant predictor for hyperglycemic relapse.
\end{abstract}

Key words: Continuous subcutaneous insulin infusion, Intensive insulin therapy, Fasting plasma glucose, Remission, Type 2 diabetes mellitus

IN RECENT years, short term intensive insulin therapy has been reported to induce long term euglycemia remission in patients with newly diagnosed type 2 diabetes mellitus (T2DM) [1-3]. In a trial led by our center [4], intensive therapy with continuous subcutaneous insulin infusion (CSII) resulted in highest remission rate $(50.3 \%)$. However, there were still a half of patients who suffered hyperglycemia relapse within 1 year in this treatment arm and even more in the other two arms. Therefore, in order to early identify those tended to get relapse and implement appropriate supplement intervention in time, it is necessary to clar-

Submitted Aug. 23, 2012; Accepted Jan. 16, 2013 as EJ12-0315 Released online in J-STAGE as advance publication Feb. 20, 2013

Correspondence to: Yanbing Li, Endocrinology and Diabetes Center, the first affiliated hospital of Sun Yat-sen University, Zhongshan Er road, 58th, Guangzhou 510080, China.

E-mail: EASD04LYB@126.com ify the underlying mechanisms and factors involved in maintenance of euglycemia or hyperglycemia relapse.

The present study aims to elucidate the factors that are responsible for remission or predict for hyperglycemia relapse after intensive insulin therapy in newly diagnosed type 2 diabetes patients.

\section{Materials and Methods}

\section{Subjects}

We analyzed the original data of a population of 188 patients with newly diagnosed type 2 diabetes who were hypoglycemic drug naïve and received short term intensive insulin therapy with CSII. This patient population comprises the participants in a study conducted by our center and those enrolled in our center in another study initiated and led by our center. All patients were diagnosed type 2 diabetes accord- 
ing to WHO diagnostic criteria (1999) in department of endocrinology, first affiliated hospital of Sun Yatsen University from September 2001 to October 2006, received intensive insulin therapy with CSII and maintained excellent glycemic control (defined as fasting blood glucose $<6.0 \mathrm{mmol} / \mathrm{L}$ and postprandial blood glucose $<8.0 \mathrm{mmol} / \mathrm{L}$ ) for 2 weeks. The patients were then instructed for life style intervention and followed up for 12 months.

\section{Measurements}

Fasting plasma glucose (FPG), post-prandial plasma glucose (PPG), glycosylated hemogroblobin A1c (HbA1c), free fatty acid (FFA), lipid profile, plasma proinsulin and insulin concentration were measured both before CSII and at the day at least 15 hours after insulin cessation with a 10-hour overnight fast. Intravenous glucose tolerance test (IVGTT) with $25 \mathrm{~g}$ glucose was performed before CSII and after insulin cessation, and serum insulin concentrations before and $1,2,4,6$, and 10 minutes after intravenous glucose administration were measured.

\section{Follow up}

After 2-week CSII intervention was completed, patients were instructed to continue intervention of diet and physical exercise only and were followed-up monthly during the initial 3 months and at 3-month intervals thereafter. Hyperglycaemia relapse was defined as either $\mathrm{FPG}>7.0 \mathrm{mmol} / \mathrm{L}$ or $2-\mathrm{h} \mathrm{PPG}>10.0$ $\mathrm{mmol} / \mathrm{L}$, which was confirmed 1 week later. The time of glycaemic remission was recorded, and patients with hyperglycaemic relapse were treated with oral hypoglycaemic agents or insulin according to guidelines. Patients who maintained optimal glycaemic control for at least 12 months without medication were defined as the remission group and those who relapsed during the 12 months of follow-up as the non-remission group.

\section{Calculations}

Homeostatic model assessments (HOMA) were applied to evaluated body insulin resistance (HOMAIR: FPG $(\mathrm{mmol} / \mathrm{L}) \times$ fasting insulin $(\mathrm{mIU} / \mathrm{L}) / 22.5)$ and $\beta$-cell function (HOMA- $\beta$ : $20 \times$ fasting insulin $(\mathrm{mIU} / \mathrm{L}) /$ [FPG (mmol/L) -3.5]). Acute insulin response (AIR) during IVGTT, which is calculated as the trapezoidal area during the first 10 minutes, was used to represent the first phase insulin secretion. The deposition index (DI): AIR/ HOMA-IR. Proinsulin/insulin ratio (PI/I) was used to assess insulin-processing function of $\beta$ cell.

\section{Statistical analysis}

Statistical analysis was performed with SPSS 13.0 program. Quantitative variables with normal distribution (Age, Body mass index (BMI), FPG, PPG, HbA1c, Total cholesterol (TCh), High density lipoprotein-cholesterol (HDL-c), Low density lipoproteincholesterol (LDL-c), FFA, PI/I) are presented as means \pm SDs, whereas skewed variables (Triglyceride (TG), HOMA-IR, HOMA- $\beta$, DI, AIR) as medians (interquartile range). Independent $T$ test was applied to compare the differences between remission and nonremission group. Paired sample test was used for the comparison of data before and after intervention. To test for the differences among 3 groups of data, ANOVA was applied. Skewed data was log transformed before statistical analysis. Multivariate Logistic regression was done to evaluate the independent predictor of 12-month remission. Cox proportional hazard analysis was performed to assess the risk level of relapse. Cumulative survivals of remission were calculated in patient groups within different FPG range, and time-to-event distributions were summarized with Kaplan-Meier curves. Statistical significance was set at $p<0.05$.

The studies were approved by the Medical research and ethic committee of Sun Yat-sen University. All patients signed the written informed consent. The study designs have been described in previous publications $[3,4]$.

\section{Results}

\section{Remission rate}

Totally 95 patients suffered hyperglycemia relapse. $62.1 \%(59 / 95)$ of hyperglycemic relapse occurred within the first 3 months after intervention, while $77.9 \%$ (74/95) within the first 6 months (Fig. 1). 93 patients had acheived 12-month euglycemic remission. The remission rates at the third, sixth and twelfth months after CSII were $68.6 \%, 60.6 \%$ and $49.5 \%$, respectively.

\section{Metabolic data, beta cell function and insulin sensitivity}

General clinical characteristics and metabolic control of all subjects were shown in Table 1. Substantial improvements in FPG, PPG, HbAlc, TCh, TG, FFA were obtained both in remission and nonremission patients. The remission group exhibited lower FPG after CSII therapy and FFA while other indices of meta- 


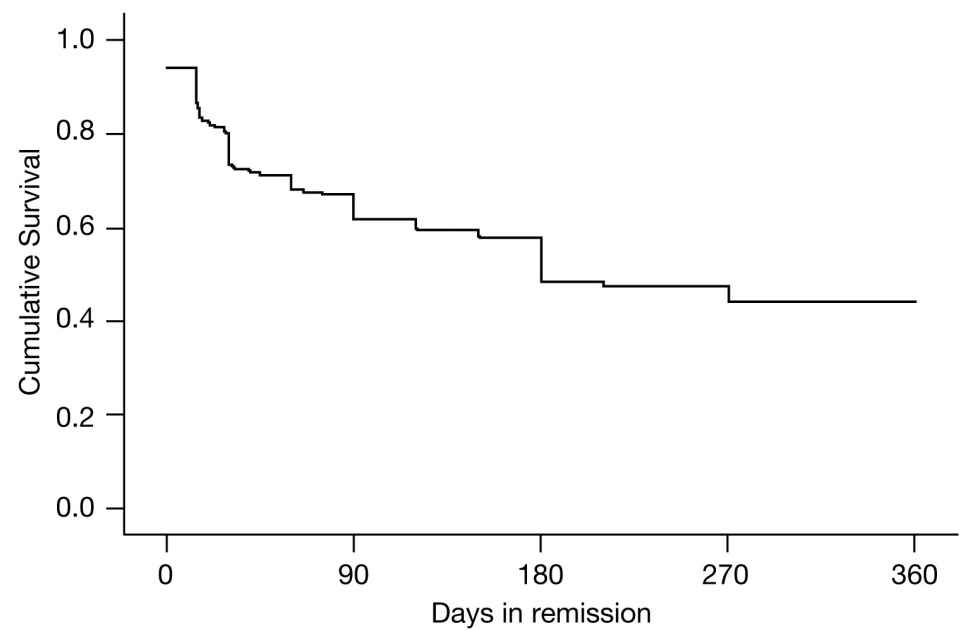

Fig. 1 Proportion of patients remaining on remission during follow-up: $68.6 \%$ at third month, $60.6 \%$ at sixth month and $49.5 \%$ at twelfth month.

Table 1 General clinical characteristics and metabolic control of remission and nonremission patients

\begin{tabular}{|c|c|c|c|}
\hline values & Remission & Nonremission & $p$ value \\
\hline $\mathrm{n}$ & $93(49.5 \%)$ & $95(50.5 \%)$ & \\
\hline Age(years) & $49.8 \pm 10.3$ & $53.4 \pm 11.4$ & 0.105 \\
\hline Gender (male/female) & $53 / 40$ & $57 / 38$ & 0.233 \\
\hline \multicolumn{4}{|l|}{ BMI $\left(\mathrm{kg} / \mathrm{m}^{2}\right)$} \\
\hline Before CSII & $25.5 \pm 3.8$ & $24.7 \pm 3.1$ & 0.110 \\
\hline After CSII & $25.5 \pm 3.7$ & $24.3 \pm 3.1 * *$ & 0.019 \\
\hline \multicolumn{4}{|l|}{$\mathrm{FPG}(\mathrm{mmol} / \mathrm{L})$} \\
\hline Before CSII & $12.6 \pm 4.6$ & $12.8 \pm 4.0$ & 0.748 \\
\hline After CSII & $6.3 \pm 1.0 *$ & $7.0 \pm 1.6^{*}$ & 0.000 \\
\hline \multicolumn{4}{|l|}{ PPG (mmol/L) } \\
\hline Before CSII & $18.9 \pm 6.2$ & $17.6 \pm 6.0$ & 0.144 \\
\hline After CSII & $8.5 \pm 1.7^{*}$ & $9.0 \pm 2.6^{*}$ & 0.073 \\
\hline \multicolumn{4}{|l|}{ HbAlc $(\%)$} \\
\hline Before CSII & $9.6 \pm 2.3$ & $9.8 \pm 2.3$ & 0.516 \\
\hline After CSII & $8.3 \pm 1.9^{*}$ & $8.4 \pm 1.6^{*}$ & 0.838 \\
\hline Reduction of $\mathrm{HbA} 1 \mathrm{c}^{\dagger}$ & $1.3 \pm 1.5$ & $1.5 \pm 1.6$ & 0.338 \\
\hline \multicolumn{4}{|l|}{$\mathrm{TCh}(\mathrm{mmol} / \mathrm{L})$} \\
\hline Before CSII & $5.5 \pm 1.1$ & $5.8 \pm 1.2$ & 0.083 \\
\hline After CSII & $5.1 \pm 1.3^{*}$ & $5.2 \pm 0.9^{*}$ & 0.478 \\
\hline \multicolumn{4}{|l|}{$\mathrm{TG}(\mathrm{mmol} / \mathrm{L})$} \\
\hline Before CSII & $1.9(1.9)$ & $1.7(1.3)$ & 0.029 \\
\hline After CSII & $1.5(0.6)^{*}$ & $1.5(0.9)^{*}$ & 0.192 \\
\hline \multicolumn{4}{|l|}{ HDL-c $(\mathrm{mmol} / \mathrm{L})$} \\
\hline Before CSII & $1.1 \pm 0.4$ & $1.2 \pm 0.3$ & 0.023 \\
\hline After CSII & $1.2 \pm 0.4$ & $1.3 \pm 0.4$ & 0.135 \\
\hline \multicolumn{4}{|l|}{ LDL-c $(\mathrm{mmol} / \mathrm{L})$} \\
\hline Before CSII & $3.1 \pm 0.9$ & $3.4 \pm 1.0$ & 0.016 \\
\hline After CSII & $3.1 \pm 1.2$ & $2.9 \pm 0.9^{*}$ & 0.296 \\
\hline \multicolumn{4}{|l|}{ FFA (mmol/L) } \\
\hline Before CSII & $0.67 \pm 0.23$ & $0.76 \pm 0.25$ & 0.156 \\
\hline After CSII & $0.58 \pm 0.19 * *$ & $0.65 \pm 0.20 * *$ & 0.033 \\
\hline
\end{tabular}

vs that before CSII $* p<0.001 * * p<0.05$

${ }^{\dagger}$ Reduction of $\mathrm{HbAlc}$ is defined as the value of HbA1c before CSII minus that after CSII

BMI, body mass index; CSII, continuous subcutaneous insulin infusion; PPG, post-prandial plasma glucose; HbA1c, glycosylated hemoglobin A1c; TCh, total cholesterol; TG, triglyceride; HDL-c, high density lipoprotein-cholesterol; LDL-c, low density lipoprotein-cholesterol; FFA, free fatty acid 
Table 2 Comparison of $\beta$ cell function and insulin sensitivity between remission and nonremission group

\begin{tabular}{lccc}
\hline values & Remission & Nonremission & $p$ value \\
\hline HOMA- $\beta$ & & & \\
$\quad$ Before CSII & $35.6(60.1)$ & $28.7(31.94)$ & 0.092 \\
$\quad$ After CSII & $118.1(122.6)^{*}$ & $86.3(68.8)^{*}$ & 0.024 \\
HOMA-IR & & & \\
$\quad$ Before CSII & $8.73(6.63)$ & $7.04(5.57)$ & 0.148 \\
$\quad$ After CSII & $3.88(3.05)^{*}$ & $3.79(3.48)^{*}$ & 0.600 \\
DI & & & \\
$\quad$ Before CSII & $-27.7(30.3)$ & $-11.9(44.5)$ & 0.069 \\
$\quad$ After CSII & $177.8(282.7)^{*}$ & $104.8(154.8)^{*}$ & 0.017 \\
AIR(pmol/L per min) & & & \\
$\quad$ Before CSII & $-230.1(309.5)$ & $-69.0(276.9)$ & 0.002 \\
$\quad$ After CSII & $733.6(1084.3)^{*}$ & $338.6(564.0)^{*}$ & 0.010 \\
PI/I & & & \\
$\quad$ Before CSII & $27.7(17.6)$ & $25.9(13.9)$ & 0.890 \\
$\quad$ After CSII & $14.5 \pm 9.1^{*}$ & $16.1 \pm 11.4^{*}$ & 0.334 \\
\hline
\end{tabular}

* vs that before CSII $p<0.001$

HOMA, homeostatic model assessment; CSII, continuous subcutaneous insulin infusion; DI, deposition index; AIR, acute insulin response; PI/I, proinsulin/insulin ratio

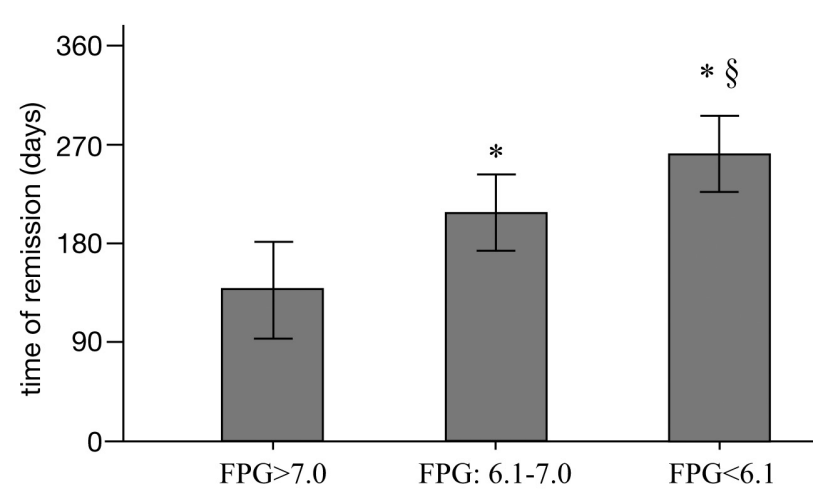

Fig. 2 Duration of remission in patients with different ranges of FPG after CSII (mmol/L):

$137.3 \pm 102.4$ days in patient group with $\mathrm{FPG}>7.0$; $207.8 \pm 144.6$ days in patient group with $6.1 \leq \mathrm{FPG} \leq 7.0$; $260.5 \pm 139.1$ days in patient group with $\mathrm{FPG}<6.1$

$* v s$ patients with $\mathrm{FPG}>7.0, p<0.001$

$\S v s$ patients with $6.1 \leq \mathrm{FPG} \leq 7.0, p=0.048$

Error bar: $95 \%$ confidence interval

FPG, fasting plasma glucose; CSII, continuous subcutaneous insulin infusion

bolic profile were comparable between the two groups.

Marked ameliorations in $\beta$ cell function and insulin sensitivity, both in remission and nonremission patients, were attained after CSII. Greater improvements in HOMA- $\beta$, DI and AIR, other than HOMA-IR, were observed in remission group, while PI/I show similar trend but did not reach statistical significance (Table 2).

All patients were stratified into three groups according FPG level measured 15 hours after insulin ces- sation (FPG after CSII). The average duration of remission was $137.3 \pm 102.4$ days in patients with $\mathrm{FPG}>7.0 \mathrm{mmol} / \mathrm{L}, 207.8 \pm 144.6$ days in those with $6.1 \mathrm{mmol} / \mathrm{L} \leq \mathrm{FPG} \leq 7.0 \mathrm{mmol} / \mathrm{L}$ and $260.5 \pm 139.1$ days in those with $\mathrm{FPG}<6.1 \mathrm{mmol} / \mathrm{L}$, respectively $(p<0.0001$, Fig. 2). Differences in metabolic control, $\beta$ cell function and insulin sensitivity among groups were explored (Table 3). PPG, HOMA $\beta$, DI, and AIR after CSII exhibited gradual declines with increasing levels of FPG.

\section{Correlation and regression}

To evaluate the relationship between the duration of remission and indices of metabolic control, $\beta$ cell function and insulin sensitivity before and after intervention, Pearson correlation was performed. Significant correlation was noted between the duration of remission and FPG after CSII $(r=-0.349, p<0.0001)$, HOMA- $\beta$ after CSII $(r=0.214, p=0.048)$.

Multivariate logistic regression showed that FPG after CSII was independent predictor of hyperglycemic relapse (Odds ratio $=1.585, p=0.001,95 \%$ CI $(1.210$, 2.076)), adjusted for age, gender, BMI.

As multivariate Cox proportional hazards regression demonstrated, compared with the patients with $\mathrm{FPG}<6.1$, risk for hyperglycemia relapse was increased $60 \%$ in those with $6.1 \leq \mathrm{FPG} \leq 7.0$ (Hazard ratio=1.60, $p=0.049,95 \% \mathrm{CI}(1.13,2.64))$, and 1.69 folds in those with FPG $>7.0$ (Hazard ratio=2.69, $p<0.0001,95 \% \mathrm{CI}$ $(1.61,4.50))$. Time to event distribution according to different ranges of FPG after CSII was shown in Fig. 3. 
Table 3 Metabolic control and $\beta$ cell indices in patients in different ranges of FPG after CSII

\begin{tabular}{|c|c|c|c|c|}
\hline \multirow[b]{2}{*}{ Values after CSII } & \multicolumn{3}{|c|}{ Fasting plasma glucose after CSII (mmol/L) } & \multirow[b]{2}{*}{$p$ value } \\
\hline & $\begin{array}{l}<6.1 \\
\mathrm{n}=65\end{array}$ & $\begin{array}{c}6.1 \sim 7.0 \\
n=70\end{array}$ & $\begin{array}{l}>7.0 \\
n=53\end{array}$ & \\
\hline \multicolumn{5}{|l|}{ PPG $(\mathrm{mmol} / \mathrm{L})$} \\
\hline Before CSII & $17.9 \pm 5.9$ & $17.7 \pm 6.0$ & $19.2 \pm 5.9$ & 0.354 \\
\hline After CSII & $8.4 \pm 2.2^{*}$ & $8.7 \pm 1.9 *$ & $9.7 \pm 2.5^{*}$ & 0.015 \\
\hline \multicolumn{5}{|l|}{$\mathrm{HbAlc}(\%)$} \\
\hline Before CSII & $9.2 \pm 1.9$ & $9.9 \pm 2.6$ & $10.0 \pm 2.2$ & 0.118 \\
\hline After CSII & $8.1 \pm 1.9^{*}$ & $8.2 \pm 1.8^{*}$ & $8.7 \pm 1.6^{*}$ & 0.173 \\
\hline \multicolumn{5}{|l|}{$\mathrm{FFA}(\mathrm{mmol} / \mathrm{L})$} \\
\hline Before CSII & $0.78 \pm 0.27$ & $0.65 \pm 0.21$ & $0.66 \pm 0.22$ & 0.021 \\
\hline After CSII & $0.61 \pm 0.19 *$ & $0.63 \pm 0.18^{*}$ & $0.66 \pm 0.23$ & 0.879 \\
\hline \multicolumn{5}{|l|}{ НОМА- $\beta$} \\
\hline Before CSII & $38.8(53.7)$ & $32.6(46.0)$ & $21.4(27.2)$ & 0.002 \\
\hline After CSII & $164.2(106.5) *$ & $86.9(70.4) *$ & $54.7(55.5) *$ & 0.000 \\
\hline \multicolumn{5}{|l|}{ HOMA-IR } \\
\hline Before CSII & $9.3(7.2)$ & $7.5(4.9)$ & $8.1(6.0)$ & 0.992 \\
\hline After CSII & $3.4(3.5) *$ & $3.8(3.0) *$ & $4.7(3.7) *$ & 0.058 \\
\hline \multicolumn{5}{|l|}{ DI } \\
\hline Before CSII & $-17.9(40.9)$ & $-20.7(30.5)$ & $-19.3(32.0)$ & 0.942 \\
\hline After CSII & $181.0(225.7) *$ & $127.2(268.0) *$ & $75.7(164.1) *$ & 0.004 \\
\hline \multicolumn{5}{|c|}{ AIR (pmol/L per min) } \\
\hline Before CSII & $-150.0(358.8)$ & $-162.9(349.1)$ & $-122.7(283.3)$ & 0.521 \\
\hline After CSII & $488.8(1230.8) *$ & $609.4(797.4) *$ & $304.7(685.3) *$ & 0.007 \\
\hline \multicolumn{5}{|l|}{$\mathrm{PI} / \mathrm{I}$} \\
\hline Before CSII & $27.2(13.7)$ & $25.1(17.2)$ & $27.5(15.8)$ & 0.800 \\
\hline After CSII & $14.4 \pm 6.6^{*}$ & $13.7 \pm 10.8 *$ & $17.9 \pm 12.3 *$ & 0.118 \\
\hline
\end{tabular}

* vs that before CSII, $p<0.001$

CSII, continuous subcutaneous insulin infusion; PPG, post-prandial plasma glucose; HbAlc, glycosylated hemoglobin A1c; FFA, free fatty acid; HOMA, homeostatic model assessment; DI, deposition index; AIR, acute insulin response; PI/I, proinsulin/insulin ratio

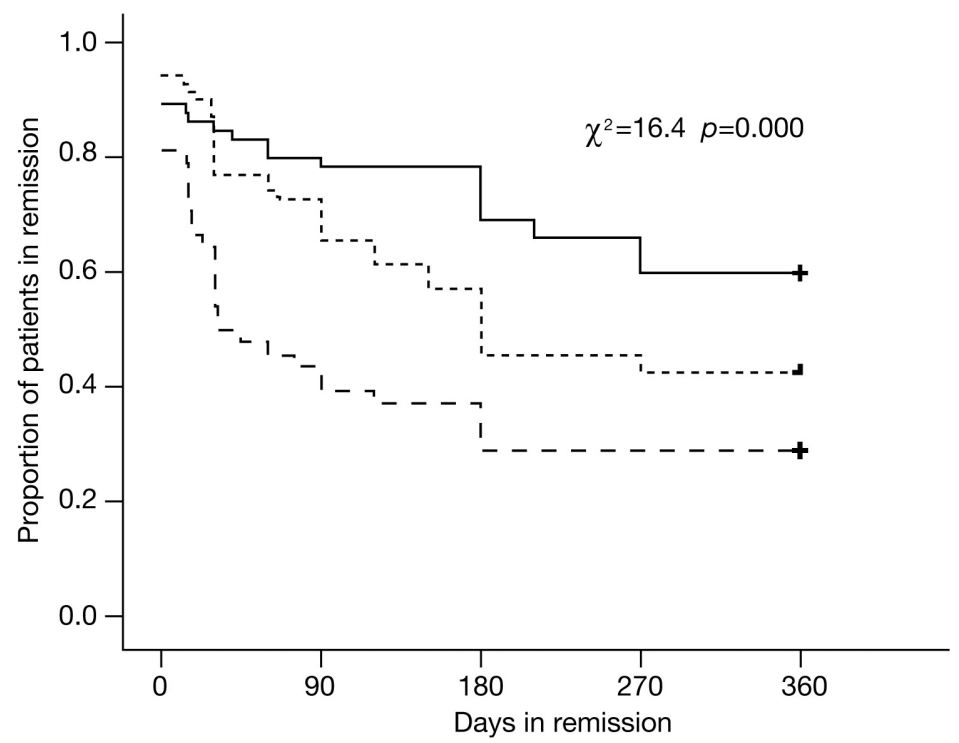

Fig. 3 Kaplan-Meier estimates of remission time in patients group in different range of FPG after CSII (mmol/L)

Solid line (upper): patient group with $\mathrm{FPG}<6.1$

Dotted line (middle): patient group with $6.1 \leq \mathrm{FPG} \leq 7.0$

Dashed line (lower): patient group with FPG $>7.0$

FPG, fasting plasma glucose; CSII, continuous subcutaneous insulin 


\section{Discussion}

The major clinical benefit of short term insulin therapy with CSII in patients with newly diagnosed T2DM is the induction of euglycemia without requirement of antidiabetic agents. As shown by our data (Fig. 1), the remission time of these patients varied from weeks to 12 months. $39.4 \%(n=74)$ of all patients suffered hyperglycemic relapse within 6 months after therapy and $50.5 \%(\mathrm{n}=95)$ within 12 months totally. In the U.K. Prospective Diabetes Study [5], all participants received only diet intervention in the first 3 months but $84.2 \%$ of them failed to attain their fasting plasma glucose of less than $6 \mathrm{mmol} / \mathrm{L}$. Although direct comparison of our study with the UKPDS data may not be appropriate, it could still be derived, from the apparently different rates of dietary failure between two studies, that intensive insulin therapy with CSII in subjects with newly diagnosed T2DM could significantly ameliorate the therapeutic response to diet interventions.

It is widely held belief [6] that glucotoxicity and lipotoxicity contribute to the progressive loss of $\beta$-cell function. In our analysis, FPG, PPG, HbAlc, TG and FFA improved significantly in all patients after days of intervention (Table 1), indicating rapid elimination of glucotoxicity and lipotoxicity by short term intensive insulin therapy with CSII. Furthermore, CSII offers insulin replacement that best mimics physiologic insulin secreting pattern, providing time and "clean" internal environment for $\beta$-cell rest and repair. So it is not surprising that HOMA- $\beta$, AIR, DI and PI/I ratio were improved significantly by CSII, indicating amelioration of insulin secreting capacity of $\beta$ cell both quantitatively and qualitatively.

On the other hand, chronic hyperglycemia per se was also able to induce and aggravate insulin resistance [7]. Relief of chronic hyperglycemia brought a reversal of peripheral insulin resistance. In our subjects, lowering blood glucose was accompanied by concomitant decrease of HOMA-IR, suggesting short term intensive insulin therapy improved insulin sensitivity by correcting hyperglycemia. So we believe that induction of remission in newly diagnosed patients with T2DM by CSII could be attributed to improvement of both $\beta$ cell function and insulin sensitivity.

In order to clarify the underlying mechanisms responsible for long term remission, we analyzed the clinical characteristics and laboratory parameters. We found that nonremission subjects possessed lower
HOMA- $\beta$, DI and AIR after therapy while HOMA-IR in two groups was comparable. In our previous research, long-term euglycemic remission was closely associated with maintenance of $\beta$ cell function. In the 10-year follow up of the Belfast diet study [8], the ongoing fall of $\beta$ cell function closely mirrored the progressive rising of fasting plasma glucose, and secondary dietary failure occurred the earliest in those with the poorest $\beta$ cell function. Similarly in UKPDS, the increasing failure of monotherapy with sulfonylurea, metformin or insulin to achieve tight glycemic control over the first 9 years following diagnosis of type 2 diabetes was consistent with the progressive decline of $\beta$-cell function [9]. Insulin sensitivity, evaluated by HOMA-IR, remained unchanged across the follow-up period in either UKPDS [10] or the Belfast study [8]. Based on these findings, it could be concluded that $\beta$ cell function, rather than insulin sensitivity, may be the determinant for long term glycemic control, and hyperglycemic relapse actually represented gradual failure of $\beta$ cell secreting function.

Currently, Hu et al. [11] found a marked decrease in HOMA-IR after intensive therapy in remission subjects but not in nonremission subjects and claimed that improvement of insulin sensitivity could be important factor that determined remission after intensive hypoglycemic therapy. Since metformin, a classic insulin sensitizer, might be included in their regimen, the discrepancy in the role of improvement of insulin resistance in long term remission could be attributed to different therapeutic regimens. Along with new understanding of the pathogenesis of T2DM in recent years, it is rational to propose that combination of intensive insulin therapy and hypoglycemic drugs that target other pathophysiologic mechanisms may maximize the clinical benefit.

An interesting finding of our analysis was the AIR presentation. AIR in remission subjects at baseline was worse than that in nonremission ones (Table 2) despite similar fasting plasma glucose before CSII in two groups (Table 1). After equivalent glycemic control by short term intensive insulin therapy (indicated by comparable $\mathrm{HbA} 1 \mathrm{c}$ and its reduction in remission and nonremission subjects), much greater recovery in AIR was achieved in remission group. Considering that first phase insulin secretion is the most sensitive marker for hyperglycemia to occur [12] and chronic hyperglycemia hampers first phase insulin secretion [13], we postulate that the extent of the deleterious effect of glu- 
cose toxicity on $\beta$ cell might vary in different diabetic individuals, and those, in whom beta cell function was impaired by glucose toxicity more profoundly, would attain greater benefit from correcting hyperglycemia by intensive insulin therapy.

In order to figure out parameters that could early identify subjects who tend to get hyperglycemic relapse, we conducted further analysis. As shown by our data, FPG after CSII was of negative correlation with the duration of remission $(r=-0.349)$, and also an independent predictor for hyperglycemic relapse $(\mathrm{OR}=1.585)$. Similar finding was reported in our previous study in another population [14]. Furthermore, when stratified into three subgroups by FPG after CSII at levels of $6.1 \mathrm{mmol} / \mathrm{L}$ and $7.0 \mathrm{mmol} / \mathrm{L}$, both longer remission time (Fig. 2) and lower hyperglycemic relapse risk (Fig. 3) were observed in subgroup with lower blood glucose level. These results suggested that FPG measured after cessation of CSII well predicted hyperglycemic relapse.

Fasting plasma glucose has been reported to predict the new onset of diabetes, even within normal range $[15,16]$. The elevations of FPG [17-19], within normal range and from normal glucose range to impaired fasting glucose and to diabetic range, are consistent with decline in $\beta$ cell function relative to insulin sensitivity. A curvilinear relationship between FPG and the relative $\beta$ cell volume (and presumably the $\beta$ cell mass) has been reported in human autopsy study [20]. In an animal experiment with streptozotocin-treated adult primates [21], FPG was found to be associated with residual $\beta$ cell area. In our patients, FPG after CSII was measured 15 hours after cessation of insulin when glucose homeostasis was maintained solely by patients' own $\beta$ cell function. Therefore the foundation of the predictive function of FPG seemed to be its representation of $\beta$ cell function to overcome insulin resistance.

In our previous study [3], recovery of first-phase insulin secretion was considered partially very helpful in maintaining prolonged near normoglycemia and AIR was responsible for long-term remission. However, first-phase insulin secretion was already blunted in subjects with fasting blood glucose $(\mathrm{FBG}) \geq 5.6 \mathrm{mmol} / \mathrm{l}$ and was virtually absent when FBG reached $6.4 \mathrm{mmol} / 1$ [12]. Therefore, in individuals with high FPG, AIR decreases little even when blood glucose keeps increasing. In these subjects, AIR will lose its predicting function. In our analysis, FPG was continuously correlated with remission time, and still provided predict- ing power when AIR failed to at a high blood glucose level. Given its easy availability, FPG was a much better parameter in clinical work.

The duration of diabetes would impact $\beta$ cell function, thus influencing remission. However we did not test the effects of duration of diabetes on remission because it is difficult to determine the accurate duration of disease in each patient. So this is a limitation of our study.

In conclusion, both improvement of $\beta$ cell function and insulin sensitivity contributed to long term remission after intensive insulin therapy in patients with newly diagnosed T2DM. Residual $\beta$ cell function, rather than insulin sensitivity, may determine the remission time. Fasting plasma glucose after intensive insulin therapy is a convenient and significant predictor for hyperglycemic relapse. In patients with higher FPG after therapy, more intensive follow up should be applied and supplemental drug therapy be implemented in time.

\section{Acknowledgment}

We would like to thank all the doctors, nurses, technicians, and patients involved for their dedication to the study.

Jianbin Liu and Juan Liu contributed to the present paper equally.

\section{Funding}

The present study was supported by the Natural Science Foundation of China (no.81070659, no.81001190); the Research Fund for the Doctoral Program of Higher Education of China (no.2009171110054); the Natural Science Foundation of Guangdong Province of China (no.1251008901000030); the Science and Technique Research Project of Guangzhou Municipality, Guangdong Province, China (no.2010J-E521); the Foundation for the Author of Excellent Doctoral Dissertation of Guangdong Province, China (no.800003226201); National Sci-Tech Support Plan (no.2009 BAI80B01).

\section{Declaration of interest}

No potential conflict of interest to be declared. 


\section{References}

1. Ilkova H, Glaser B, Tunckale A, Baqriacik N, Cerasi E (1997) Induction of long-term glycemic control in newly diagnosed type 2 diabetic patients by transient intensive insulin treatment. Diabetes Care 20:13531356.

2. Ryan EA, Imes S, Wallace C (2004) Short-term intensive insulin therapy in newly diagnosed type 2 diabetes. Diabetes Care 27: 1028-1032.

3. LiY, Xu W, Liao Z, Yao B, Chen X, et al. (2004) Induction of long-term glycemic control in newly diagnosed type 2 diabetic patients is associated with improvement of $\beta$-cell function. Diabetes Care 27: 2597-2602.

4. Weng J, Li Y, Xu W, Shi L, Zhang Q, et al. (2008) Effect of intensive insulin therapy on beta-cell function and glycaemic control in patients with newly diagnosed type 2 diabetes: a multicentre randomised parallel-group trial. Lancet 371: 1753-1760.

5. UKPDS Group (1990) United Kingdom Prospective Diabetes Study 7: response of fasting plasma glucose to diet therapy in newly presenting type II diabetic patients. Metabolism 39: 905-912.

6. Leahy JL (2005) Pathogenesis of type 2 diabetes mellitus. Arch Med Res 36: 197-209.

7. Rossetti L (1995) Glucose toxicity: the implications of hyperglycemia in the pathophysiology of diabetes mellitus. Clin Invest Med 18: 255-260.

8. Levy J, Atkinson AB, Bell PM, McCance DR, Hadden DR (1998) Beta-cell deterioration determines the onset and rate of progression of secondary dietary failure in type 2 diabetes mellitus: the 10-year follow-up of the Belfast Diet Study. Diabet Med 15: 290-296.

9. UKPDS group (1995) United Kingdom Prospective Diabetes Study 13: Relative efficacy of randomly allocated diet, sulphonylurea, insulin, or metformin in patients with newly diagnosed non-insulin dependent diabetes followed for three years. BMJ 310: 83-88.

10. UKPDS group (1995) United Kingdom prospective diabetes study 16. Overview of 6 years' therapy of type II diabetes: a progressive disease. Diabetes 44: 12491258.

11. Hu Y, Li L, Xu Y, Yu T, Tong G, et al. (2011) Shortterm intensive therapy in newly diagnosed type 2 diabetes partially restores both insulin sensitivity and $\beta$-cell function in subjects with long-term remission. Diabetes Care 34: 1848-1853.

12. Brunzell JD, Robertson RP, Lerner RL, Hazzard WR, Ensinck JW, et al. (1976) Relationships between fasting plasma glucose levels and insulin secretion during intravenous glucose tolerance tests. $J$ Clin Endocrinol Metab 42: 222-229.

13. Leahy JL, Bonner-Weir S, Weir GC (1992) Beta-cell dysfunction induced by chronic hyperglycemia. Current ideas on mechanism of impaired glucose-induced insulin secretion. Diabetes Care 15: 442-455.

14. Xu W, Li Y, Deng W, Hao Y, Weng J (2009) Remission of hyperglycemia following intensive insulin therapy in newly diagnosed type 2 diabetic patients: a long-term follow-up study. Chin Med J (Engl) 122: 2554-2559.

15. Tirosh A, Shai I, Tekes-Manova D, Israeli E, Pereg D, et al. (2005) Normal fasting plasma glucose levels and type 2 diabetes in young men. $N$ Engl J Med 353: 14541462.

16. Nichols GA, Hillier TA, Brown JB (2008) Normal fasting plasma glucose and risk of type 2 diabetes diagnosis. Am J Med 121: 519-524.

17. Tfayli H, Lee S, Arslanian S (2010) Declining beta-cell function relative to insulin sensitivity with increasing fasting glucose levels in the nondiabetic range in children. Diabetes Care 33: 2024-2030.

18. Dagogo-Jack S, Askari H, Tykodi G (2009) Glucoregulatory physiology in subjects with low-normal, high-normal, or impaired fasting glucose. $J$ Clin Endocrinol Metab 94: 2031-2036.

19. Bi Y, Zeng L, Zhu D, Yan J, Zhang Y, et al. (2012) Association of $\beta$-cell function and insulin sensitivity with fasting and 2-h plasma glucose in a large Chinese population. Diabetes Obes Metab 14: 174-180.

20. Ritzel RA, Butler AE, Rizza RA, Veldhuis JD, Butler PC (2006) Relationship between beta-cell mass and fasting blood glucose concentration in humans. Diabetes Care 29: 717-718.

21. Saisho Y, Butler AE, Manesso E, Galasso R, Zhang L, et al. (2010) Relationship between fractional pancreatic beta cell area and fasting plasma glucose concentration in monkeys. Diabetologia 53: 111-114. 